\title{
Chondroitin sulfate functionalized mesostructured silica nanoparticles as biocompatible carriers for drug delivery
}

This article was published in the following Dove Press journal:

International Journal of Nanomedicine

3 October 2012

Number of times this article has been viewed

\section{Juqun $X i^{1}$ \\ Jin Qin ${ }^{2}$ \\ Lei $\mathrm{Fan}^{2}$}

'Department of Pharmacology, Yangzhou University Medical Academy, Yangzhou, People's Republic of China; ${ }^{2}$ School of Chemistry and Chemical Engineering, Yangzhou University, Yangzhou, People's Republic of China
Correspondence: Lei Fan School of Chemistry and Chemical Engineering, Yangzhou University, Yangzhou, 225002, People's

Republic of China

Tel +86-5 | 4-87992233

Fax +86-5I4-8734|733

Email fanlei@yzu.edu.cn
Abstract: Mesoporous silica nanoparticles (MSNs) have garnered a great deal of attention as potential carriers for therapeutic payloads. Here, we report a pH-responsive drug-carrier based on chondroitin sulfate functionalized mesostructured silica nanoparticles (NMChS-MSNs) ie, the amidation between NMChS macromer and amino group functionalized MSNs. The prepared nanoparticles were characterized using dynamic light scattering, fourier transform infrared spectroscopy and transmission electron microscopy. The resultant NMChS-MSNs were uniform spherical nanoparticles with a mean diameter of approximately $74 \mathrm{~nm}$. Due to the covalent graft of hydrophilic and $\mathrm{pH}$ responsive NMChS, the NMChS-MSNs could be well dispersed in aqueous solution, which is favorable to being utilized as drug carriers to construct a $\mathrm{pH}$-responsive controlled drug delivery system. Doxorubicin hydrochloride (DOX), a well-known anticancer drug, could be effectively loaded into the channels of NMChS-MSNs through electrostatic interactions between drug and matrix. The drug release rate of DOX@NMChS-MSNs was pH dependent and increased with the decrease of $\mathrm{pH}$. The in vitro cytotoxicity test indicated that NMChS-MSNs were highly biocompatible and suitable to use as drug carriers. Our results imply that chondroitin sulfate functionalized nanoparticles are promising platforms to construct the $\mathrm{pH}$-responsive controlled drug delivery systems for cancer therapy.

Keywords: mesoporous silica nanoparticle, $\mathrm{pH}$ sensitive, chondroitin sulfate, drug delivery

\section{Introduction}

Nanoscale drug delivery systems (DDS) have achieved advantages by overcoming the challenges of common cancer treatments, ${ }^{1,2}$ they can perform as a vehicle protecting the therapeutic agent from the biological milieu and improve cellular uptake and accumulation inside tumor sites. Up to date, many materials, eg, liposomes, block copolymers, dendrimers, and various inorganic nanomaterials, have been utilized as drug carriers in DDS. ${ }^{3-6}$ Among them, mesoporous silica nanoparticles (MSNs) have attracted more and more attention as a promising component, ${ }^{7-13}$ they are excellent candidates for many biomedical applications owing to their high specific surface area, large pore volume, tunable pore structures and well-defined surface property for modification.

Despite their promise, however, recent reports highlight the potential toxicity of unmodified MSNs due to the interactions of surface silanols with cellular membranes. ${ }^{14-16}$ This toxicity can be reduced by coating the nanoparticles with polymer shells. The polymer shells can provide colloidal stability, handle for chemoligation (targeting moieties) and improve the blood circulation lifetimes, which are crucial for efficient in vivo drug delivery. Various polymers have been reported as coating shells 
of MSNs, such as chitosan, ${ }^{17,18}$ poly(ethylene glycol) (PEG), ${ }^{19}$ poly(acrylic acid) (PAA), ${ }^{20}$ poly(4-vinyl pyridine) (PVP), ${ }^{21}$ poly(L-lysine) (PLL), ${ }^{22}$ poly(N-isopropylacrylamide), ${ }^{23}$ poly (lactic acid) (PLA) ${ }^{24}$ either in their native forms or as conjugates. However, the applicability of these functionalized MSNs is largely restricted to their compositions and the coating materials, whereby the loading efficiency is usually not high enough for a practical usage and the polymer shell also limits both drug loading and release from MSNs. Therefore, efforts should still be made to develop safe and facile approaches for the fabrication of functionalized MSNs with a variety of potential biomolecular payloads.

Chondroitin sulfate $(\mathrm{ChS})$ is an important structural component in connective tissues and cartilage. It is a copolymer of $D$-glucuronic acid and sulfated $N$-acetyl- $D$-galactosamine in $\mathrm{C} 4$ or $\mathrm{C} 6$ and belongs to the group of glycosaminoglycans (GAGs), which are primarily located on the surface of cells or in the extracellular matrix. ${ }^{25,26} \mathrm{ChS}$ can be degraded by anaerobic bacteria, namely Bacteroides thetaiotaomicron and Bacteroides ovatus, which are residents of the large intestine. This character suggests that $\mathrm{ChS}$ is potentially a good candidate for usage as a drug carrier. ${ }^{27-30}$ Recently, we used a method of interfacial polymerization in emulsion to fabricate chondroitin sulfatebased nanocapsules for loading of indomethacin. ${ }^{31}$ The shell of nanocapsules consisted of the cross-linked $\mathrm{ChS}$ chains, and showed a much higher drug loading capacity. Our recent study also showed that the nanogels fabricated of chondroitin sulfate could exhibit promising $\mathrm{pH}$-responsive properties. ${ }^{32}$ Therefore, it can be imagined that the combination of MSNs and $\mathrm{ChS}$ polymer as carriers could realize the high loading capacity and pH-triggered controlled release of drug simultaneously, which would be a potential and promising strategy to design a stimuliresponsive codelivery system of drug or gene.
Herein, we report a new strategy to prepare a $\mathrm{pH}$-responsive NMChS functionalized MSNs (NMChS-MSNs) by the amidation reaction of NMChS macromers with amino groups modified MSNs. (Scheme 1). We first synthesized a macromer named as $O$-maleyl chondroitin sulfate $(\mathrm{NMChS}$ ) (Scheme $\mathrm{S} 1)$. To obtain the animated MSNs $\left(\mathrm{MSNs}-\mathrm{NH}_{2}\right)$, we used bifunctional (3-aminopropyl) triethoxysilane (APTES), and then MSNs-NH $\mathrm{N}_{2}$ were activated by 1-ethyl-3-(3-dimethylaminopropyl)carbodiimide (EDC), then followed by the addition of positively charged NMChS to form covalent bonding between primary amine of $\mathrm{MSNs}-\mathrm{NH}_{2}$ and carbonyl groups of the NMChS macromers. An acrylamide group in NMChS macromer made the polymer chains around the silica surface to be cross-linked possible. Subsequently, a covalently crosslinked NMChS shell was synthesized at room temperature by addition of $\mathrm{K}_{2} \mathrm{~S}_{2} \mathrm{O}_{3} / \mathrm{NaHSO}_{3}$, and then NMChS-MSNs could be obtained. Doxorubicin hydrochloride (DOX) was chosen as a model drug in this study to assess the drug loading and releasing behaviors of NMChS-MSNs. In vitro cellular cytotoxicity test was performed to evaluate the biocompatibility of NMChS-MSNs, and the cytotoxic effect of drug-loaded DOX@NMChS-MSNs to HeLa cells was also investigated.

\section{Materials and methods Materials}

Chondroitin sulfate (ChS, oral grade, $\mathrm{Mn}=\sim 50000$ by GPC) powder was supplied by Shanxi Sciphar Biotechnology Co, Ltd (Xi'an, China). The analytical grade reagents of maleic anhydride (MA), $\mathrm{NaHSO}_{3}$, (3-aminopropyl) triethoxysilane (APTES), tetraethyoxysilane (TEOS), cetyltrimethylammonium bromide (CTAB), potassium persulfate (KPS) and $\mathrm{NaOH}$ were obtained from Sinopharm Chemical Reagents Co, Ltd (Shanghai, China). KPS was re-crystallized from

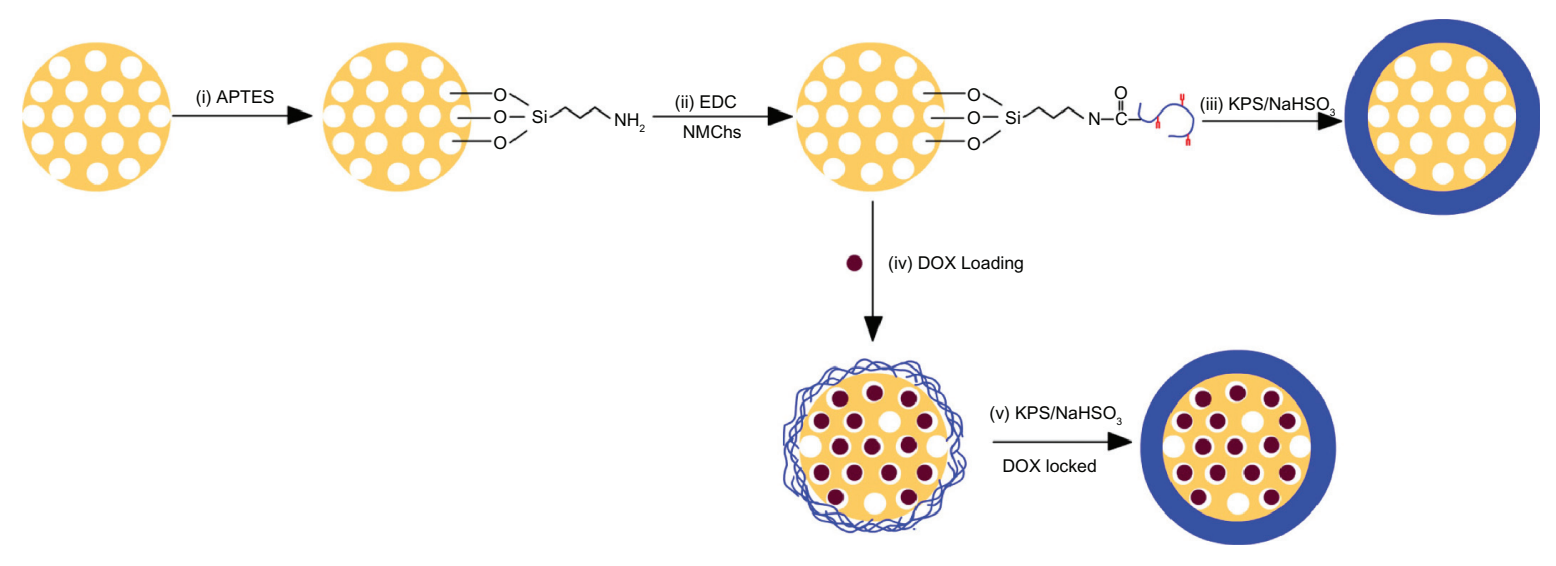

Scheme I Schematic procedure for preparation of $O$-maleyl chondroitin sulfate functionalized mesoporous silica nanoparticles (NMChS-MSNs) for drug loading. Abbreviations: APTES, (3-aminopropyl) triethoxysilane; EDC, I-ethyl-3-(3-dimethylaminopropyl) carbodiimide hydrochloride; NMChS, O-maleyl chondrotin sulfate; KPS, potassium persulfate; $\mathrm{NaHSO}$, sodium bisulfite; DOX, doxorubicin. 
water and used after vacuum drying. Doxorubicin (DOX) in the form of hydrochloride salt was obtained from Beijing Huafeng United Technology Company (Beijing, China). MTT (3-(4,5-dimethylthiazol-2-yl)-2,5-diphenyltetrazolium bromide) assay and other biological reagents were purchased from Invitrogen Corp. (USA). All other reagents were of analytical grade and used without further purification.

\section{Methods}

\section{Synthesis of NMChS}

$O$-maleyl chondroitin sulfate $(\mathrm{NMChS})$ was prepared as similar to the method of Zhu A. (Scheme S1). ${ }^{33}$ In a typical synthesis, chondroitin sulfate powder (1.0 g) was first dissolved in $100 \mathrm{~mL}$ aqueous solution and transferred to a three necked flask. The maleic anhydride (MA) were dissolved in $5 \mathrm{~mL}$ of acetone, and then the maleic anhydrideacetone solution was added to the reaction flask drop wise over $20 \mathrm{~min}$ at $65^{\circ} \mathrm{C}$. After that, the reaction was allowed to stand at $70^{\circ} \mathrm{C}$ for another $12 \mathrm{~h}$. Later, the reaction mixture was cooled to room temperature and precipitated by adding excess amount of acetone several times. After washing by acetone, the precipitate was collected and dried at $45^{\circ} \mathrm{C}$ in vacuum for $24 \mathrm{~h}$.

\section{Synthesis of MSNs}

MSNs were synthesized via a sol-gel chemistry using cetyltrimethylammonium bromide (CTAB) as templates. In a flask, $0.28 \mathrm{~g}$ of $\mathrm{NaOH}$ and $1.0 \mathrm{~g}$ of CTAB in sequence were completely dissolved into $480 \mathrm{~mL}$ of deionized water under vigorous stirring at $80^{\circ} \mathrm{C}$. After the solution became clear, $5 \mathrm{~mL}$ of TEOS was added dropwise with the whole dropping time of about $15 \mathrm{~min}$. The vigorous stirring was continued for $20 \mathrm{~h}$, and then milk-white as-synthesized materials were collected by centrifugation. In order to remove the surfactant, the as-synthesized materials were refluxed in a mixed solution of $500 \mathrm{~mL}$ ethanol and $5 \mathrm{~mL}$ hydrochloric acid at $78^{\circ} \mathrm{C}$ for $12 \mathrm{~h}$, then centrifugalized and washed for several times with ethanol. The same reflux operation was repeated for three times. The final products were dried at $80^{\circ} \mathrm{C}$ in vacuum for $24 \mathrm{~h}$.

\section{Synthesis of NMChS-MSNs}

Firstly, $0.2 \mathrm{~g}$ of MSNs was added to $40 \mathrm{~mL}$ of ethanol containing $0.5 \mathrm{~mL}$ of APTES. After being stirred at room temperature for $24 \mathrm{~h}$, the mixture was extensively washed with ethanol and dried at $80^{\circ} \mathrm{C}$ to obtain the aminated MSNs (MSNs-NH ${ }_{2}$ ). Next, to activate the amine groups, $\operatorname{EDC}\left(0.1 \mathrm{~mol} \cdot \mathrm{L}^{-1}\right)$ was added to the MSNs-NH $2\left(5.0 \mathrm{mg} \cdot \mathrm{mL}^{-1}\right.$ in water, $\left.20 \mathrm{~mL}\right)$, the above mixture was kept for $1 \mathrm{~h}$, and then NMChS solution $\left(2.5 \mathrm{mg} \cdot \mathrm{mL}^{-1}\right)$ was added. After $8 \mathrm{~h}$ of stirring at room temperature, the mixture was centrifuged, washed twice with water to remove excess EDC and un-reacted $\mathrm{NMChS}$, and re-dispersed in water. Subsequently, the polymerization cross linking reaction was initiated by addition of $25 \mu \mathrm{L}$ of $\mathrm{KPS} / \mathrm{NaHSO}_{3}$ solution $(1.0 \mathrm{mg} / 1.0 \mathrm{mg})$ under a nitrogen atmosphere at $40^{\circ} \mathrm{C}$, and performed for $6 \mathrm{~h}$. After that, the NMChS functionalized MSNs were collected by centrifugation for further use.

\section{Drug adsorption into MSNs and NMChS-MSNs}

In a typical MSNs drug loading process: 12.5 milligrams of MSNs was mixed with $5 \mathrm{~mL}$ of DOX solution in PBS. After stirring for $24 \mathrm{~h}$ under dark conditions, the DOX-loaded MSNs (DOX@MSNs) were centrifuged and washed with PBS. In a typical NMChS-MSNs drug loading process (Scheme 1): 12.5 milligrams of NMChS-MSNs before cross-linking were mixed with $5 \mathrm{~mL}$ of DOX solution in PBS, after stirring for $24 \mathrm{~h}$ under dark conditions, the DOX-loaded nanoparticles were centrifuged, washed with PBS and re-dispersed in $5 \mathrm{~mL}$ PBS by addition of $\mathrm{KPS} / \mathrm{NaHSO}_{3}$ solution for cross linking reaction. Finally, the DOX@NMChS-MSNs were collected by centrifugation. The obtained DOX@MSNs or DOX@ NMChS-MSNs were used for subsequent tests of in vitro DOX release and cytotoxicities against Hela cells. To evaluate the DOX-loading efficiency, the supernatant and washed solutions were collected and the residual DOX content was measured by using UV-vis measurement at a wavelength of $490 \mathrm{~nm}$. The loading content (LC\%) and loading efficiency (LE\%) of DOX can be calculated as follows:

Drug loading content $(\%)=\frac{\text { weight of drug in } \mathrm{MSNs}}{\text { weight of } \mathrm{MSNs}} \times 100 \%$ (1)

Drug loading efficiency $(\%)=\frac{\text { weight of drug in MSNs }}{\text { weight of feed drug }} \times 100 \%$

\section{In vitro release of drug}

The in vitro simulated release of DOX was executed in pH 5.0, 6.8 and 7.4 buffer solutions, respectively. The above-prepared DOX@MSNs or DOX@NMChS-MSNs $\left(2.5 \mathrm{mg} \cdot \mathrm{L}^{-1}, 2.5 \mathrm{~mL}\right)$ was immersed in $20 \mathrm{~mL}$ PBS solutions at $37^{\circ} \mathrm{C}$ and shaken at $100 \mathrm{rpm}$. At certain time intervals, $2 \mathrm{~mL}$ of PBS was taken out by centrifugation to test the concentration of the released DOX and $2 \mathrm{~mL}$ of fresh PBS was added to the tube containing the DOX@MSNs 
or DOX@NMChS-MSNs. The aliquot was centrifuged to obtain a clear supernatant and analyzed using UV-visible spectroscopy at $490 \mathrm{~nm}$.

\section{In vitro cytotoxicity}

The cytotoxicity of NMChS-MSNs or DOX@NMChSMSNs against Hela cells was evaluated by MTT assay. Hela cells were seeded in 96-well plates at 10000 cells per well in $100 \mu \mathrm{L}$ of DMEM medium and incubated at $37^{\circ} \mathrm{C}$ in $5 \% \mathrm{CO}_{2}$ atmosphere for $24 \mathrm{~h}$. The culture medium was replaced with $100 \mu \mathrm{L}$ of fresh medium containing DOX@NMChS-MSNs or free DOX at $\mathrm{pH}$ 7.4. After $24 \mathrm{~h}$ treatment, the medium was replaced by fresh DMEM at $\mathrm{pH} 7.4$ and followed by addition of $25 \mu \mathrm{L}$ of MTT stock solution ( $5 \mathrm{mg} \cdot \mathrm{mL}^{-1}$ in PBS). After incubation for an additional $2 \mathrm{~h}, 100 \mu \mathrm{L}$ of the extraction buffer (20\% SDS in 50\% DMF, pH 4.7) was added to the wells and incubated for $4 \mathrm{~h}$. The absorbance of the solution was measured at $570 \mathrm{~nm}$ using a Bio-Rad 680 microplate reader and cell viability was normalized to that of Hela cells cultured with blank culture medium. The results were compared with those of the control wells to determine relative cell viability.

\section{Characterization}

Transmission electron microscopy (TEM) images were obtained on a TECNAI-12 transmission electron microscope (Philips, Netherland), and samples for TEM measurements were made by casting one drop of the sample's ethanol solution on copper grids. Field emission scanning electron microscopy (FE-SEM) observation was carried out on an Hitachi S4800 electron microscope (Hitachi, Japan). Powder X-ray diffraction (XRD) patterns were collected for the powdered samples using a AXS D8 diffractometer (Bruker, Germany). The particle size was characterized by photon correlation spectroscopy (Zetasizer Nano ZS-90, Malvern Instruments, UK). Raw data were subsequently correlated to mean hydrodynamic size by cumulants analysis (Z-average mean). The Zeta potentials of all nanoparticles were analyzed by laser doppler anemometry (Zetasizer Nano ZS-90, Malvern Instruments, UK). All samples were run in triplicate, and the mean averages and standard deviations were calculated. Fourier transform infrared (FT-IR) spectra were recorded on a Tensor 27 spectrophotometer (Bruker, Germany). The UV-vis spectra were recorded by using a UV-2550 spectrophotometer (Shimadzu, Japan) in the wavelength range of 200-600 nm. ${ }^{1} \mathrm{H}$ NMR spectra were recorded on a NMR spectrometer (ANAVCE DMX600, Bruker, Germany) with $\mathrm{D}_{2} \mathrm{O}$ as solvent, working at $600 \mathrm{MHz}$.

\section{Results and discussion Structure of NMChS macromer}

Structure changes of chondroitin sulfate after maleoyl-acylation were first confirmed by FT-IR spectra (Figure S1). The representative absorption peaks for nascent ChS (Figure S1A) can be adapted from the publication: ${ }^{34} \mathrm{OH}$ and $\mathrm{NH}$ stretching $\left(3426 \mathrm{~cm}^{-1}\right), \mathrm{CH}_{2}$ stretching $\left(2926 \mathrm{~cm}^{-1}\right)$, amide I $\left(1634 \mathrm{~cm}^{-1}\right)$, $\mathrm{COO}^{-} v^{\text {as }}$ stretching $\left(1560 \mathrm{~cm}^{-1}\right), \mathrm{COO}^{-} \mathrm{v}^{\mathrm{s}}$ stretching $\left(1412 \mathrm{~cm}^{-1}\right), \mathrm{SO}_{4}{ }^{2-}$ related modes $\left(1248 \mathrm{~cm}^{-1}\right), \mathrm{C}-\mathrm{O}$ stretching $\left(1088 \mathrm{~cm}^{-1}\right.$ and $\left.1068 \mathrm{~cm}^{-1}\right)$. In the spectrum of maleic anhydride (Figure S1B), there are representative absorption peaks for anhydrides at 1849 and $1778 \mathrm{~cm}^{-1}$. Accompanying the disappearances of the peaks for anhydrides, we find a new absorption peak at $1738 \mathrm{~cm}^{-1}$ in the spectra of NMChS (Figure S1C), which is due to the characteristic ester absorption band. Meanwhile, significant enhanced absorption peaks at $1560 \mathrm{~cm}^{-1}\left(\mathrm{COO}^{-} \mathrm{v}^{\text {as }}\right.$ stretching) and at $1068 \mathrm{~cm}^{-1}(\mathrm{C}-\mathrm{O}$ stretching) are obvious. These changes shown in FT-IR spectra indicate that maleoyl-acylation has successfully bonded with the ChS molecule.

The evidence of MA substitution on $\mathrm{ChS}$ was also observed by ${ }^{1} \mathrm{H}-\mathrm{NMR}$ as shown in Figure S2. A peak at 6.23 ppm is due to the two protons attached to the double bond $(\mathrm{CH}=\mathrm{CH})$, which is not present in the virgin chondroitin sulfate molecule. So, the results of ${ }^{1} \mathrm{H}$ NMR also illuminate that the maleoyl-acylation has successfully bonded with the $\mathrm{ChS}$ molecule. Furthermore, according to the N/C weight ratios of ChS (0.121) and NMChS (0.075) detected by elemental analysis, the MA grafting degree is calculated as $62 \%$. After completed the synthesis, the acrylamide group is brought to the NMChS macromer, which makes the polymer chains around the silica surface to be cross-linked possible.

\section{The morphology and mesostructure of MSNs and NMChS-MSNs}

The schematic preparation process of NMChS-MSNs is illustrated in Scheme 1. Firstly, MSNs were synthesized via the sol-gel chemistry using CTAB as templates. Subsequently, MSNs were functionalized with amino groups by a reaction with APTES, which would afford targets to the consequent modification with NMChS. Then, the aminated MSNs were activated by EDC, and followed by the addition of negatively charged NMChS to form covalent bonding between primary amine and carboxyl groups in NMChS. Finally, the polymerization-cross linking was initiated by the addition of $\mathrm{KPS} / \mathrm{NaHSO}_{3}$ and the cross-linked chondroitin sulfate functionalized mesostructured silica nanoparticles could be 

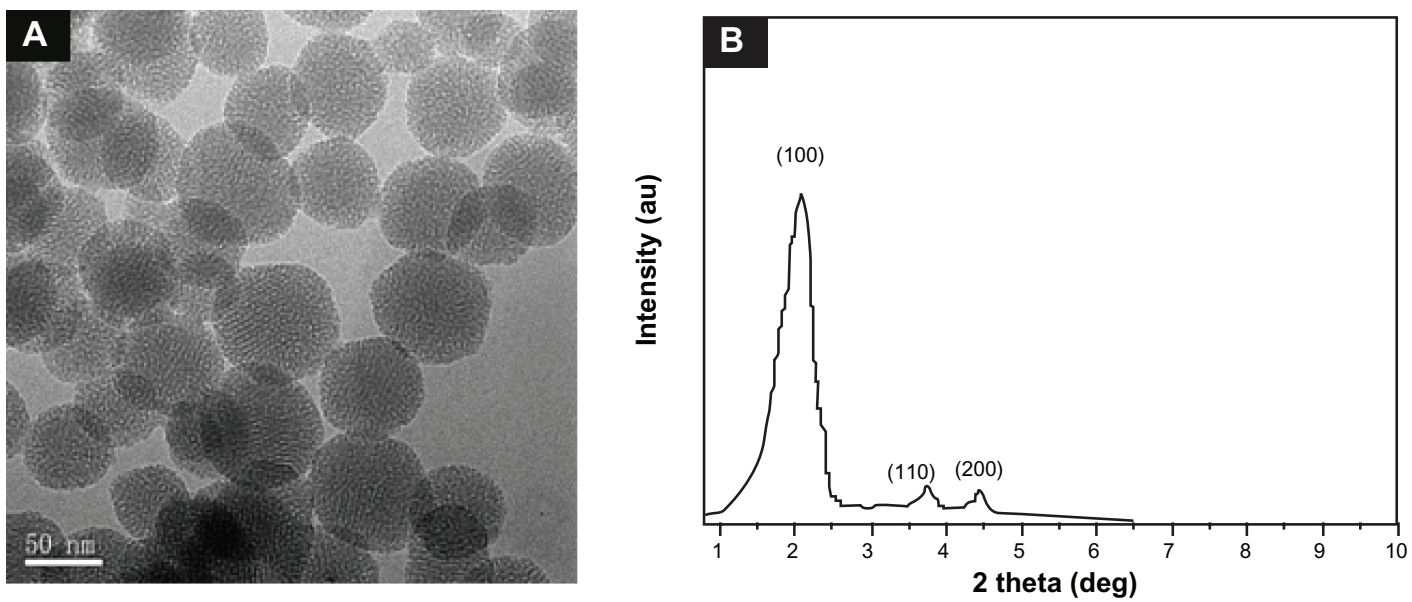

Figure I TEM images (A) and XRD pattern (B) of MSNs.

Abbreviations: TEM, transmission electron microscopy; XRD, powder X-ray diffraction; MSNs, mesoporous silica nanoparticles.

obtained. This synthetic strategy provides a covalent polymer shell without the use of catalysts and surfactants and requires mild conditions compatible with a variety of potential biomolecular payloads. According to our previous work, ${ }^{35}$ we hypothesize that NMChS wrapping around MSNs will act as $\mathrm{pH}$ responsive shell ensuring release of guest molecules in acidic $\mathrm{pH}$ conditions, and this $\mathrm{pH}$ responsiveness is believed due to the differences in protonation state of chondroitin sulfate under different $\mathrm{pH}$ conditions.

As shown in transmission electron microscopy (TEM) images (Figure 1A), the prepared MSNs are uniform spherical nanoparticles with a mean diameter of approximately $60 \mathrm{~nm}$. FE-SEM images (Figure S3) confirm that MSNs are uniform spheres, which are suitable for further modification. The ordered mesoporous structure of the nanoparticles is further confirmed by a small angle XRD measurement (Figure 1B). Three well-resolved diffraction peaks, assigned as (100), (110) and (200) planes respectively, are clearly observed in the XRD pattern of MSNs, which is consistent with the characteristic diffraction patterns of MCM-41 type MSNs.

After the MSNs were functionalized by $\mathrm{NMChS}$ (Figure 2) indicate that the synthesis yielded individually encapsulated MSNs displaying a thin polymeric shell, which is absent on uncoated nanoparticles, and an about $10 \mathrm{~nm}$ polymer coating can be observed around the silica particle after polymerization. TEM measurements indicate that the diameters of the uncoated and polymer-coated MSNs are $60 \pm 8$ and $74 \pm 16 \mathrm{~nm}$, respectively. Particle size distribution of MSNs in PBS solution measured by dynamic light scattering (DLS) is relatively broad (mean dimmer $=212.6 \pm 13.9$, PDI $=0.684$ ) (Figure $3 \mathrm{~A})$. The particle size is larger than that of the TEM observation, which may have resulted from the aggregation of MSNs in PBS solution. Compared with the size distribution of MSNs, the NMChS-MSNs have a relatively narrow particle size distribution (mean dimmer $=255.4 \pm 9.1 \mathrm{PDI}=0.245)($ Figure $3 \mathrm{~B})$. This suggests that the NMChS modification improves the dispersity of MSNs in PBS solution. After MSNs and NMChS-MSNs solutions in PBS are statically placed for $12 \mathrm{~h}$, almost all MSNs are located in the bottom, while most of NMChS-MSNs still suspend in PBS solution (Figure 3C and D). Therefore, the DLS and TEM data indicate that this polymer coating procedure can avoid agglomeration of the nanoparticles into the larger (micrometer-scale) aggregates, which is a critical factor in biomedicine applications.

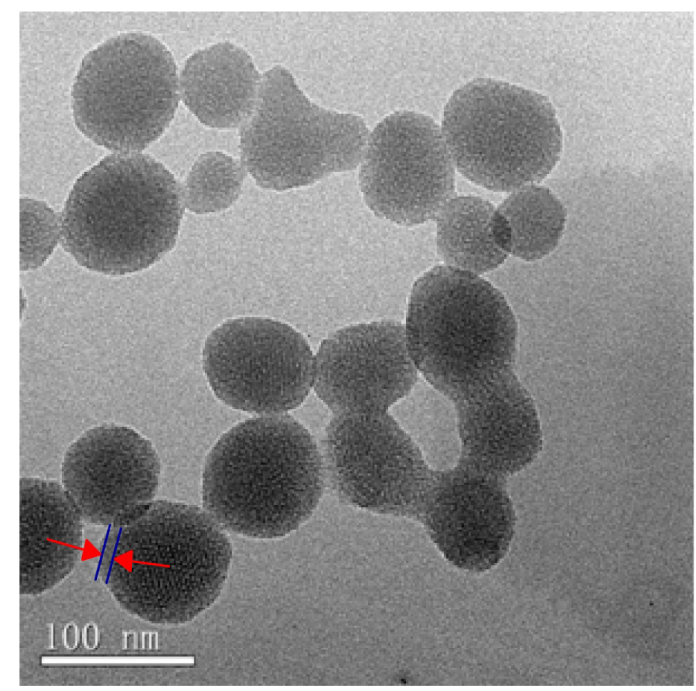

Figure 2 TEM images of NMChS functionalized MSNs.

Abbreviations: TEM, transmission electron microscopy; NMChS, O-maleyl chondroitin sulfate; MSNs, mesoporous silica nanoparticles. 
A
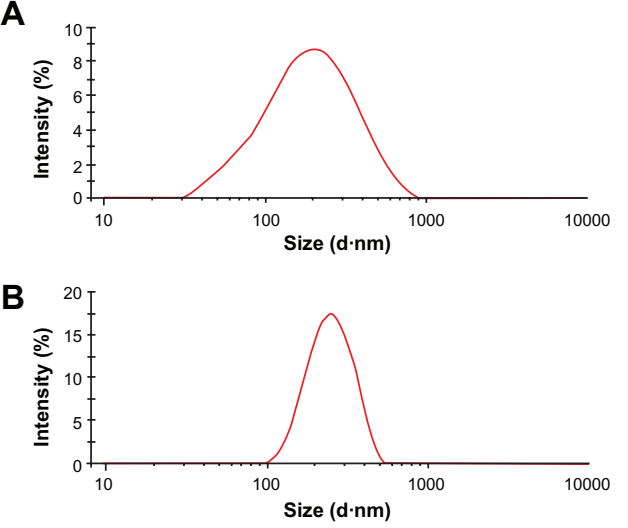
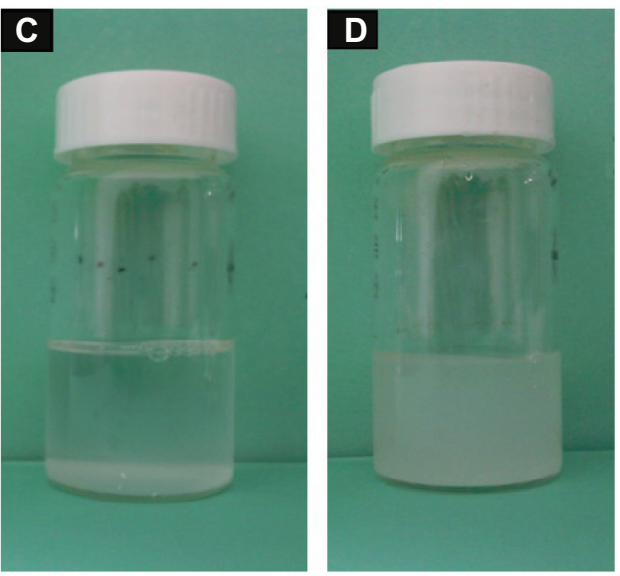

Figure 3 Particle size distributions of MSNs (A) and NMChS-MSNs (B) measured by DLS, and photographs of MSNs (C) and NMChS-MSNs (D) solutions after 12 hours placement.

Abbreviations: TEM, transmission electron microscopy; MSNs, mesoporous silica nanoparticles; NMChS-MSNs, O-maleyl chondroitin sulfate functionalized mesoporous silica nanoparticles; DLS, dynamic light scattering.

Successful coating of NMChS onto MSNs was also detected by zeta potential measurements. Figure 4 shows zeta potentials of MSNs, MSNs-NH ${ }_{2}$ and NMChS-MSNs in PBS solution, respectively. It can be found that zeta potentials are changed after the NMChS modification. The zeta potential of MSNs is $-11.9 \pm 3.5 \mathrm{mV}$, while it is $8.6 \pm 4.6 \mathrm{mV}$ for MSNs- $\mathrm{NH}_{2}$ and $-35.1 \pm 5.8 \mathrm{mV}$ for NMChS-MSNs. This suggests that NMChS have bounded to MSNs, and change the surface potential of MSNs. Such high zeta potential value of in PBS solution also explains that particles are very well dispersed in the solution and do not aggregate so much. Here, FT-IR spectra were used to further confirm the NMChS modification. The FT-IR spectra for coated and uncoated MSNs display the absorption band at around $1071 \mathrm{~cm}^{-1}$, which is assigned to $\mathrm{Si}-\mathrm{O}$ bond in silica (Figure 5). The peaks at $1648,796,967,1087$ and $1237 \mathrm{~cm}^{-1}$ in all curves

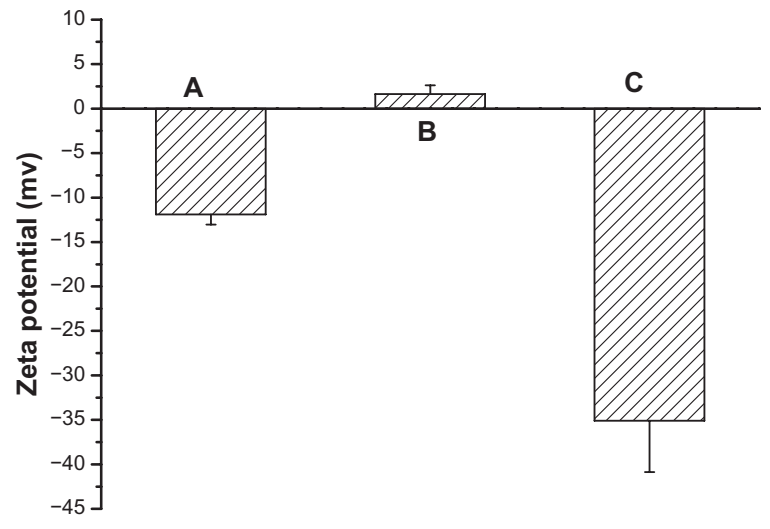

Figure 4 Zeta potentials of MSNs (A), MSNs-NH PBS solution ( $\mathrm{pH} 7.4)$.

Note: Mean \pm SD, $\mathrm{n}=3$.

Abbreviations: MSNs, mesoporous silica nanoparticles; NMChS-MSNs, O-maleyl chondroitin sulfate functionalized mesoporous silica nanoparticles; $\mathrm{MSNs}-\mathrm{NH}_{2}$, aminated mesoporous silica nanoparticles. are attributed to the stretching vibration of $\mathrm{O}-\mathrm{H}$, the flexible vibrations of $\mathrm{Si}-\mathrm{O}$, the stretching vibration of $\mathrm{Si}-\mathrm{OH}$ and $\mathrm{Si}-\mathrm{O}-\mathrm{Si}$, respectively. ${ }^{35} \mathrm{NMChS}-\mathrm{MSN}$ s show the adsorption bands of native NMChS at about $1416 \mathrm{~cm}^{-1}$. That is attributed to the $\mathrm{COO}^{-}$symmetry stretching, which is not absent in MSNs FI-IR spectra. Meanwhile, a significant enhanced absorption peak at $1634 \mathrm{~cm}^{-1}$ (amide I) is obvious. All the above results indicate the presence of NMChS in modified MSNs, and the covalently cross-linked polymer shell can improve the stability of MSNs.

The physicochemical properties of NMChS-MSNs were also tested at different $\mathrm{pH}$ values and temperatures. When the NMChS-MSNs are dispersed in buffer solution with various $\mathrm{pH}$ values, the diameter and zeta potential of the NMChS-MSNs are increased with an increase of the $\mathrm{pH}$ value (Figure $6 \mathrm{~A}$ ). At $\mathrm{pH}=1.0$ the diameter of

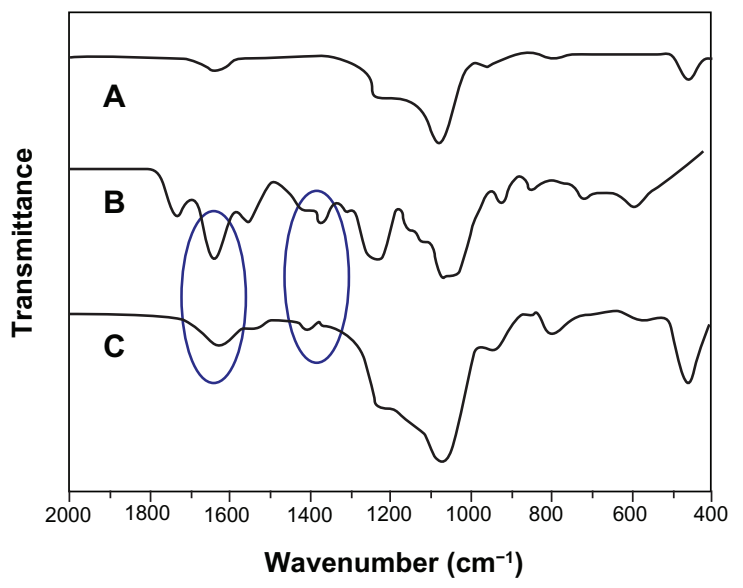

Figure 5 FT-IR spectra of MSNs (A), NMChS (B) and NMChS-MSNs (C). Abbreviations: MSNs, mesoporous silica nanoparticles; NMChS-MSNs, O-maleyl chondroitin sulfate functionalized mesoporous silica nanoparticles. 

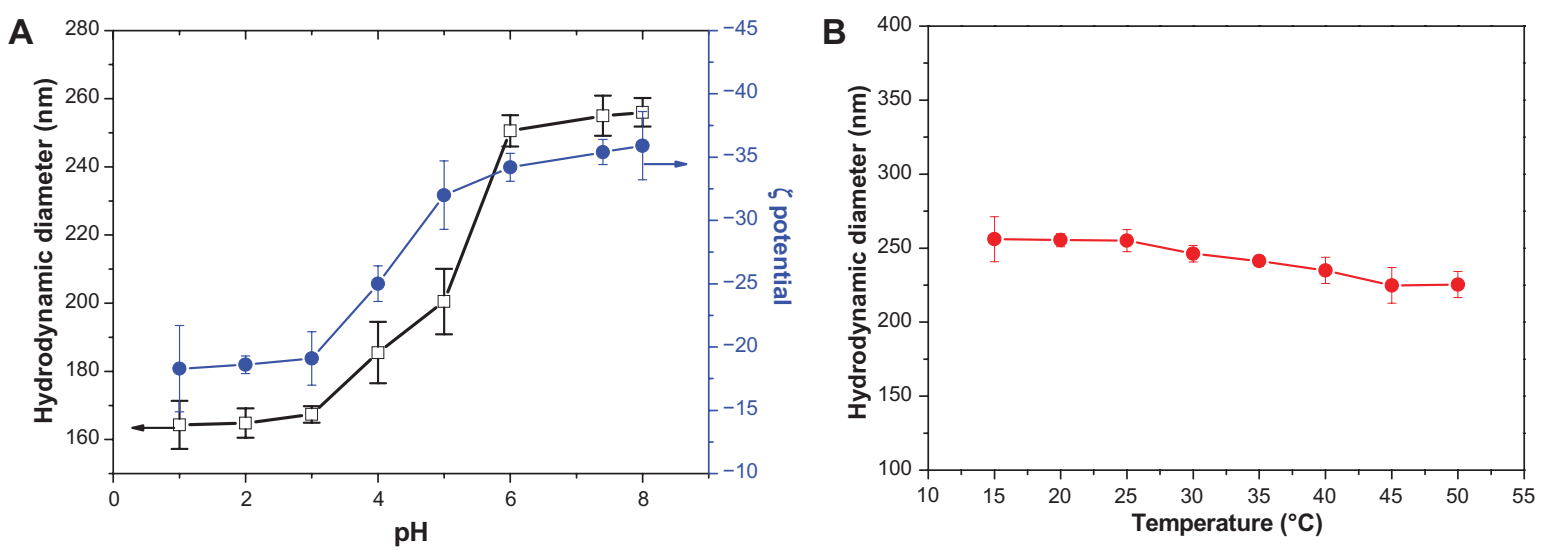

Figure 6 (A) Various in size of NMChS-MSNs in different values of $\mathrm{pH}$ at $25^{\circ} \mathrm{C}$; (B) Various in size of NMChS-MSNs at different values of temperatures at $\mathrm{pH} 7.4$. Note: Mean $\pm S D, n=3$.

Abbreviations: NMChS-MSNs, O-maleyl chondroitin sulfate functionalized mesoporous silica nanoparticles.

the NMChS-MSNs is $164 \pm 7.1 \mathrm{~nm}$ and the zeta potential is $-18.3 \pm 3.4 \mathrm{mV}$. When the $\mathrm{pH}$ value is changed to 7.4 , the diameter of the NMChS-MSNs increases to $255 \pm \mathrm{nm}$ and the zeta potential increases to $-35.9 \pm 2.7 \mathrm{mV}$. When the $\mathrm{pH}$ value of solution is lower, the carboxylic groups $(-\mathrm{COOH})$ are located on the surface of NMChS-MSNs. The network among molecular chains exhibits intense structure and shape under strong acidic condition and shows the smaller diameter and the lower zeta potential. However, with increasing the media $\mathrm{pH}$ values, carboxylic groups are dissociated into the ionized form $\left(-\mathrm{COO}^{-}\right)$. Static repulsion increases on account of the dissociation of the carboxylic acid groups under alkaline conditions, leading to the swelling of the NMChS crosslinked layer and increase in size. Likewise, no significantly further condensation occurred below $\mathrm{pH}<3$ because of complete protonation of the carboxyl groups. These results indicate that the NMChS-MSNs can exhibit promising $\mathrm{pH}-$ responsive properties.

The effect of the temperature on the NMChS-MSNs stability was evaluated in a range from $15^{\circ} \mathrm{C}$ to $50^{\circ} \mathrm{C}$. For this study, a solution of NMChS-MSNs was placed in the DLS cell, and the temperature in the chamber was scanned with increments of $5^{\circ} \mathrm{C}$ and 20 min stabilization time at each temperature. Afterward, the cell was left to cool to $15^{\circ} \mathrm{C}$, and the size distribution was again recorded. A plot of average particle size versus temperature is shown in Figure 6B. A modest decrease in the average particle diameter with increasing the temperature is observed. These results show that a rise in temperature does not destroy the polymer network between segments consisting of NMChS monomer units, and the NMChS polymer shells keep their structure well and do not collapse even at $50^{\circ} \mathrm{C}$. This result indicates that NMChS-MSNs are stable in the temperature range of $15^{\circ} \mathrm{C}-50^{\circ} \mathrm{C}$.

\section{Calculation of loading capacity and release behavior}

We chose doxorubicin (DOX) as a model drug due to its wellcharacterized spectral characteristics and its use in chemotherapy. As it is known, the $\mathrm{pKa}$ of DOX is 8.6. At $\mathrm{pH} 7.4$, the positively charged DOX will bind with the negatively charged NMChS to form the DOX@MSNs-NMChS complex by electrostatic interaction, which can enhance the loading of drug into the MSNs pores. We first investigated the drug-loading capacity of the polymer-coated MSNs by comparing the total amount of drug loaded before and after polymer coating. When we fixed the concentration of DOX to be $0.25 \mathrm{mg} \cdot \mathrm{mL}^{-1}$, the loading of DOX in polymer-coated MSNs is only slightly lower (about $68 \%$ of total DOX added) compared with the uncoated MSNs (about $\sim 74 \%$ of total DOX added). DOX loading contents in MSNs and NMChS-MSNs are 68.1 and $74.0 \mu \mathrm{g}$ DOX per $1.0 \mathrm{mg}$ of MSNs, respectively. This suggests that the polymer shell does not reduce the drug loading capacity of MSNs as drastically as other reported polymer shell MSNs systems, which is an additional advantage of our technique over previously reported coating methods. ${ }^{35,36}$

We then determined the loading content (LC\%) and the loading efficiency (LE\%) of DOX at different weight ratios

Table I DOX loading content and loading efficiency of NMChS-MSNs

\begin{tabular}{lll}
\hline $\begin{array}{l}\text { DOX } \\
\left(\mathbf{m g} \cdot \mathbf{~ m L}^{-1}\right)\end{array}$ & $\begin{array}{l}\text { Loading } \\
\text { content }\end{array}$ & $\begin{array}{l}\text { Loading } \\
\text { efficiency }\end{array}$ \\
\hline 0.25 & 6.8 & 68.1 \\
0.5 & 11.9 & 59.5 \\
1.0 & 14.1 & 35.2 \\
\hline
\end{tabular}

Note: The concentration of NMChS-MSNs is $2.5 \mathrm{mg} \cdot \mathrm{mL}^{-1}$.

Abbreviations: DOX, doxorubicin; MNChS-MSNs, O-maleyl chondroitin sulfate functionalized mesoporous silica nanoparticles. 
of DOX/NMChS-MSNs. The results are listed in Table 1. The LC\% increases with the DOX concentration in the PBS solution due to the increased concentration gradient. The maximum LC\% of $14.1 \%$ is reached at the DOX concentration of $1.0 \mathrm{mg} \cdot \mathrm{mL}^{-1}$. The value of $\mathrm{LE} \%$ decreases with the increasing of DOX concentration presumably, because the maximum absorption of the drug is reached. The maximum of $\mathrm{LE} \%$ is about $68.1 \%$. These results indicate that NMChSMSNs possess high drug loading efficiency to DOX.

Besides drug loading, drug release is another important parameter for drug efficacy. The release profiles of DOX@ MSNs and DOX@NMChS-MSNs were performed at pH values of 7.4 (blood circulation), 6.8 (tumor extracellular) and 5.5 (endosomes) for $24 \mathrm{~h}$ at $37^{\circ} \mathrm{C}$. Figure $7 \mathrm{~A}$ demonstrates that the DOX release rate is obviously $\mathrm{pH}$ dependent and increases with the decrease of $\mathrm{pH}$. At $\mathrm{pH}$ 7.4 , the release amount is quite low and only approximately $16 \%$ is released in $24 \mathrm{~h}$. At $\mathrm{pH} 6.8$, the release profile curve levels off after $12 \mathrm{~h}$ and the release amount is $37 \%$ in $24 \mathrm{~h}$. Intriguingly note that when $\mathrm{pH}$ decreases to 5.5, a faster release behavior is obtained and the release amount reaches $61 \%$ in $24 \mathrm{~h}$, which is almost four times of that at $\mathrm{pH}$ 7.4. This is because the drug release from the NMChSMSNs is mainly determined by the effect of electrostatic interaction between DOX and polymer nanoshell. The $\mathrm{pKa}$ of DOX is 8.3 , so it is positively charged at the selected three $\mathrm{pH}$ values. On the whole, the higher the $\mathrm{pH}$ of the medium is, the more negative charges are on the surface of the NMChS-MSNs, the stronger attraction exists between the positively charged DOX and the negatively charged carriers, so the more difficult for the loaded DOX to be released out of the NMChS functionalized MSNs.

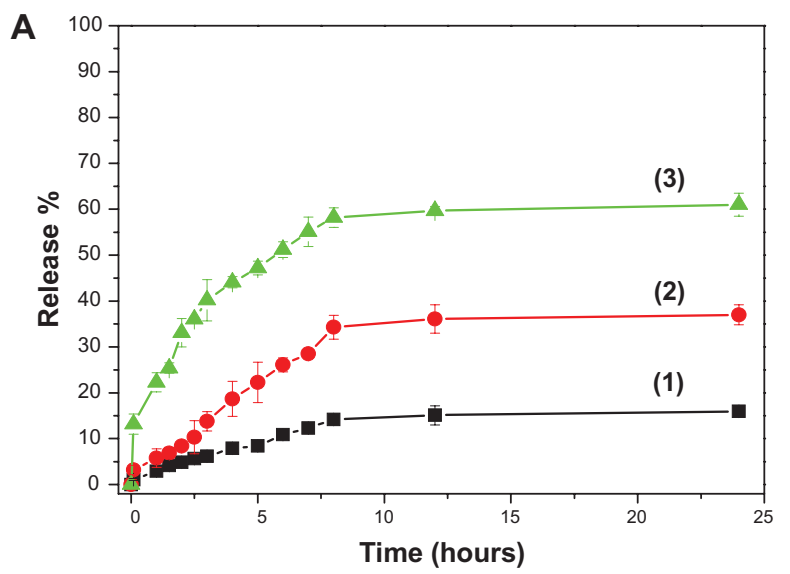

Figure 7 pH-dependent release kinetics of (A) DOX@NMChS-MSNs and (B) DOX@MSNs.

Notes: (I) $\mathrm{pH}=7.4$; (2) $\mathrm{pH}=6.8$; (3) $\mathrm{pH}=5.5$ (Mean $\pm \mathrm{SD}, \mathrm{n}=3$ ).

Abbreviations: DOX, doxorubicin; MNChS-MSNs, O-maleyl chondroitin sulfate functionalized mesoporous silica nanoparticles

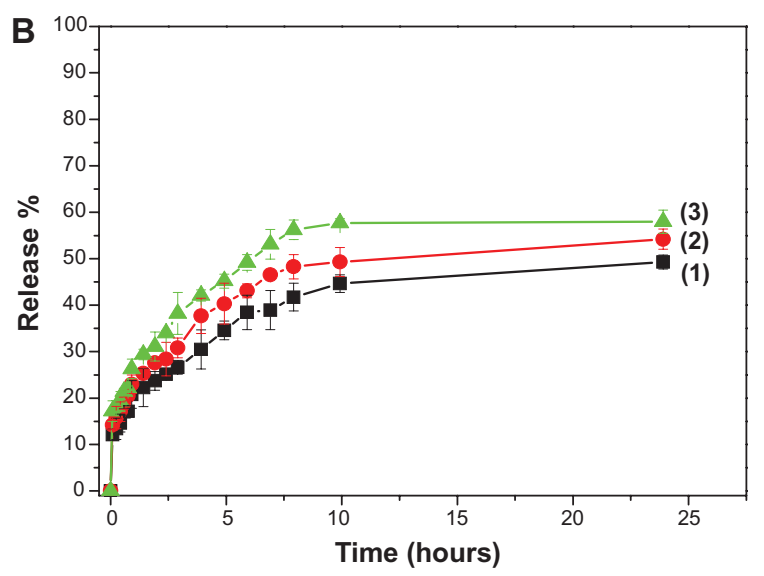

As a comparison, the drug release experiments of DOX@ MSN were also carried out. Figure 7B shows the drug release of DOX@MSNs at pH values of 7.4,6.8 and 5.5. Obviously, the differences in release amount among different $\mathrm{pH}$ are not as significant as that of DOX@NMChS-MSNs with the released drug amount of $51 \%, 54 \%$ and $58 \%$ in corresponding $\mathrm{pH}$ values after 24 h. Therefore, DOX@NMChS-MSNs display a more pronounced $\mathrm{pH}$ dependent property than DOX@MSNs, and more drug molecules could be released for DOX@NMChS-MSNs system at lower pH solution. Considering the fact that the tumor tissues are more acidic than the normal tissues, the prepared DOX@NMChS-MSNs would be able to minimize the side effect of DOX. Combined with the specific drug release behavior and simultaneous high loading capacity and encapsulation efficiency for DOX, the NMChS-MSNs are highly expected to be used in cancer treatment without frequent interval medication administrations.

\section{In vitro cell assay}

The results of DOX loading and releasing studies motivated us to further investigate the in vitro cellular cytotoxicity. The in vitro cytotoxicity of DOX@NMChS-MSNs to HeLa cells was investigated by MTT assay. When the pure NMChS-MSNs are $0.5,5,10,100 \mu \mathrm{g} \cdot \mathrm{mL}^{-1}$, the cell viabilities are $98 \% \pm 5 \%, 95 \% \pm 5 \%, 94 \% \pm 12 \%, 92 \% \pm 9 \%$ for $24 \mathrm{~h}$, respectively. As shown in Figure 8, the blank carrier NMChS-MSNs show no cytotoxicity on the HeLa cells even at $100 \mu \mathrm{g} \cdot \mathrm{mL}^{-1}$ after incubation for $24 \mathrm{~h}$, suggesting that the NMChS-MSNs are biocompatible. Conversely, when the HeLa cells are treated with either the suspension of DOX-loaded NMChS-MSNs or a solution of pure DOX at high DOX concentration, significant decrease of the cancer 

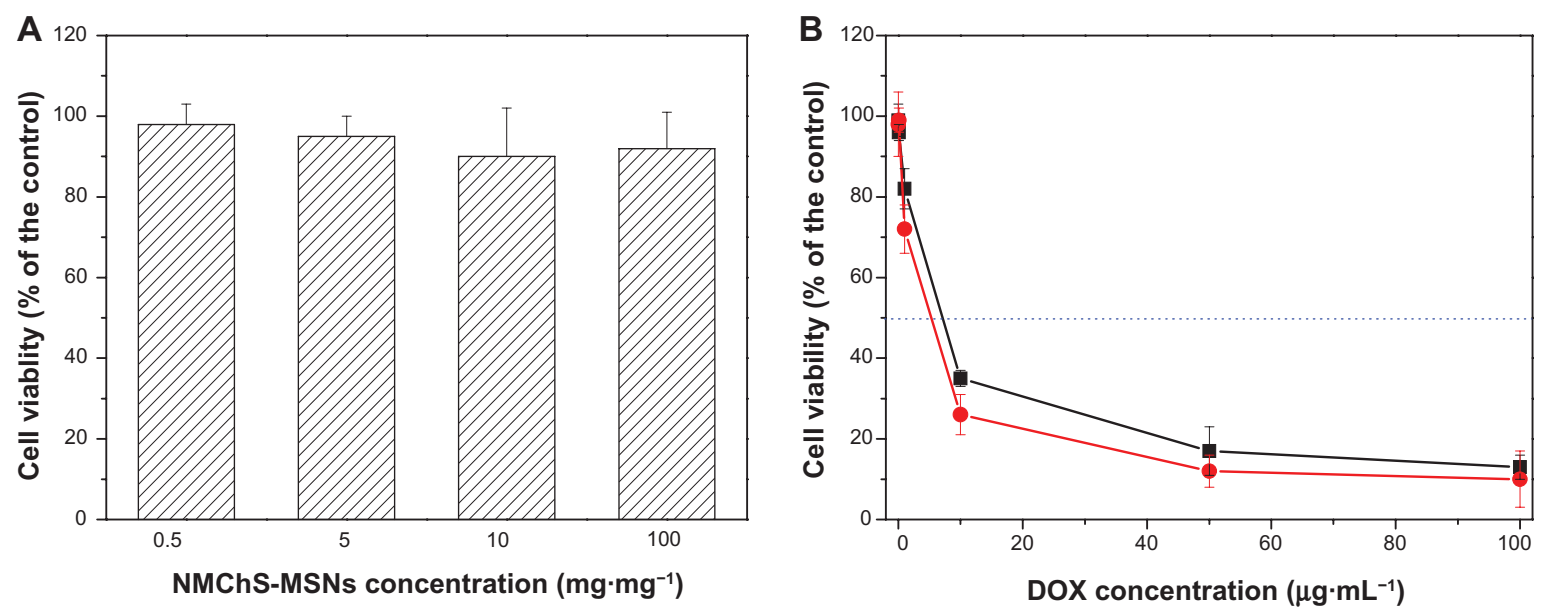

Figure 8 Relative cell viabilities of HeLa cells incubated with different concentrations of (A) NMChS-MSNs for 24 h, and (B) DOX and DOX@ NMChS-MSNs for 24 h. Note: Mean $\pm S D, n=3$.

Abbreviations: DOX, doxorubicin; MNChS-MSNs, O-maleyl chondroitin sulfate functionalized mesoporous silica nanoparticles.

cell viability is presented. DOX@NMChS-MSNs exhibit higher inhibition activity after $24 \mathrm{~h}$ culture in comparison with DOX in free form. The DOX dose required for $50 \%$ cellular growth inhibition $\left(\mathrm{IC}_{50}\right)$ is only $5.2 \mu \mathrm{g} \cdot \mathrm{mL}^{-1}$ with DOX-loaded nanogels, which is $7.1 \mu \mathrm{g} \cdot \mathrm{mL}^{-1}$ of that required for treatment with DOX in free form. Enhanced inhibition of DOX-loaded nanogels to tumor cell growth would be advantageous in lowering the dose of DOX in application. This result indicates that the N NMChS-MSNs may be a good carrier for drug delivery to the cell.

\section{Conclusion}

In conclusion, we presented a facile and effective method to coat chondroitin sulfate-based macromer onto amined mesoporous silica nanoparticles to generate $\mathrm{pH}$ responsive nanocarriers. The loading and releasing behaviors of DOX were investigated. NMChS-MSNs exhibit a high drug loading efficiency, due to the strong electrostatic interaction between NMChS and DOX. Detailed characterization studies show that chondroitin sulfate is effectively anchored on the surface of the silica preventing release of DOX under undesirable conditions. It is apparent from release studies that DOX releases under mild acidic conditions due to the decrease of the electrostatic interactions between drug and matrix. The in vitro cellular cytotoxicity test demonstrates that the NMChS-MSNs are highly biocompatible and suitable to utilize as drug carriers. Furthermore, DOX@NMChSMSNs show a more efficient cytotoxicity than free DOX to HeLa cells. The unique polymer coated MSN enables it not only to be a $\mathrm{pH}$-responsive nanocarrier, but also to possess tailored release profile. Therefore, the polymer modified
MSNs system is a promising strategy toward their potential application as drug delivery vehicles.

\section{Acknowledgements}

This work is supported by the Priority Academic Program Development of Jiangsu Higher Education Institutions, the National Natural Scientific Foundations of China (21073156), the University Natural Science Foundation of Jiangsu Province (10KJB150020 and 12KJB350006), and the Key Laboratory of Environmental Materials and Environmental Engineering of Jiangsu Province (017375003579).

\section{Disclosure}

The authors report no conflicts of interest in this work.

\section{References}

1. Sultana Y, Maurya DP, Iqbal Z, et al. Nanotechnology in ocular delivery: current and future directions. Drugs Today (Barc). 2011;47(6): 441-455.

2. Talekar M, Kendall J, Denny W, et al. Targeting of nanoparticles in cancer: drug delivery and diagnostics. Anticancer Drugs. 2011;22(10): 949-962.

3. Parveen S, Misra R, Sahoo SK. Nanoparticles: a boon to drug delivery, therapeutics, diagnostics and imaging. Nanomedicine. 2012;8(2) 147-166.

4. Hosseinkhani H, Tabata Y. Self assembly of DNA nanoparticles with polycations for the delivery of genetic materials into cells. J Nanosci Nanotechnol. 2006;6(8):2320-2328.

5. Jiang W, Kim BY, Rutka JT, Chan WC. Advances and challenges of nanotechnology-based drug delivery systems. Expert Opin Drug Deliv. 2007;4(6):621-633.

6. Hosseinkhani H, Hosseinkhani M, Gabrielson NP, et al. DNA nanoparticles encapsulated in 3D tissue-engineered scaffolds enhance osteogenic differentiation of mesenchymal stem cells. J Biomed Mater Res A. 2008;85(1):47-60.

7. Yang PP, Gai SL, Lin J. Functionalized mesoporous silica materials for controlled drug delivery. Chem Soc Rev. 2012;41(9):3679-3698. 
8. Faiza S, Fabiola P, Annemarie HM, et al. Mesoporous silica nanoparticles as a compound delivery system in zebrafish embryos. Int $J$ Nanomedicine. 2012;7:1875-1890.

9. Singh N, Karambelkar A, Gu L, et al. Bioresponsive mesoporous silica nanoparticles for triggered drug release. J Am Chem Soc. 2011; 133(49):19582-19585.

10. Tsai CH, Vivero-Escoto JL, Slowing II, et al. Surfactant-assisted controlled release of hydrophobic drugs using anionic surfactant templated mesoporous silica nanoparticles. Biomaterials. 2011;32(26): 6234-6244.

11. Sarparanta M, Bimbo LM, Rytkönen J, et al. Intravenous delivery of hydrophobin-functionalized porous silicon nanoparticles: stability, plasma protein adsorption and biodistribution, Mol Pharmaceutics. 2012;9(3):654-663.

12. Pablo B, Ibane A, Yolanda F, et al. Surface-modified silica nanoparticles for tumor-targeted delivery of camptothecin and its biological evaluation. J Control Release. 2011;156(2):246-257.

13. Liu YT, Mi Y, Zhao J, et al. Multifunctional silica nanoparticles for targeted delivery of hydrophobic imaging and therapeutic agents. Int J Pharm. 2011;421(2):370-378.

14. Slowing II, Vivero-Escoto JL, Wu CW, et al. Mesoporous silica nanoparticles as controlled release drug delivery and gene transfection carriers. Adv Drug Deliv Rev. 2008;60(11):1278-1288.

15. He Q, Zhang Z, Gao Y, et al. Intracellular localization and cytotoxicity of spherical mesoporous silica nano- and microparticles. Small. 2009;5(23):2722-2729.

16. He QJ, Zhang ZW, Gao F, et al. In vivo biodistribution and urinary excretion of mesoporous silica nanoparticles: Effects of particle size and PEGylation. Small. 2011;7(2):271-280.

17. Popat A, Liu J, Lu GQ, Qiao SZ. pH-responsive drug delivery system based on chitosan coated mesoporous silica nanoparticles. J Mater Chem. 2012;22(22):11173-11178.

18. Chen F, Zhu YC. Chitosan enclosed mesoporous silica nanoparticles as drug nano-carriers: Sensitive response to the narrow $\mathrm{pH}$ range. Micropor Mesopor Mater. 2012;150(1):83-89.

19. He QJ, Zhang JM, Shi JL, Zhu ZY, et al. The effect of PEGylation of mesoporous silica nanoparticles on nonspecific binding of serum proteins and cellular responses. Biomaterials. 2010;31(6): 1085-1092.

20. Yuan L, Tang QQ, Yang D, et al. Preparation of pH-Responsive mesoporous silica nanoparticles and their application in controlled drug delivery. J Phys Chem C. 2011;115(20):9926-9932.

21. Liu R, Liao PH, Liu JK, Feng PY. Responsive polymer-coated mesoporous silica as a $\mathrm{pH}$-sensitive nanocarrier for controlled release. Langmuir. 2011;27(6):3095-3099.
22. Zhu YF, Meng WJ, Gao H, et al. Hollow mesoporous silica/poly(Llysine) particles for co-delivery of drug and gene with enzyme-triggered release property. J Phys Chem C. 2011;115(28):13630-13636.

23. Fu Q, Rao GVR, Ista LK, et al. Control of molecular transport through stimuli-responsive ordered mesoporous materials. Adv Mater. 2003;15(15):1262-1266.

24. Tang J, Slowing II, Huang YL, et al. Poly(lactic acid)-coated mesoporous silica nanosphere for controlled release of venlafaxine. J Colloid Interface Sci. 2011;360(2):488-496.

25. Mikami KT, Uyama T, Mizuguchi S, Nomura K, Kitagawa H. Recent advances in the structural biology of chondroitin sulfate and dermatan sulfate. Curr Opin Struc Biol. 2003;13(5):612-620.

26. Ketschek AR, Haas C, Gallo G, Fischer I. The roles of neuronal and glial precursors in overcoming chondroitin sulfate proteoglycan inhibition. Exp Neurol. 2012;35(2):627-637.

27. Bagari R, Bansal D, GulbakeA, et al. Chondroitin sulfate functionalized liposomes for solid tumor targeting. J Drug Target. 2011;19(4):251-257.

28. Lai JY, Li YT, Cho CH, et al. Nanoscale modification of porous gelatin scaffolds with chondroitin sulfate for corneal stromal tissue engineering. Int J Nanomedicine. 2012;7:1101-1114.

29. Li FY, Na K. Self-assembled chlorin e6 conjugated chondroitin sulfate nanodrug for photodynamic therapy. Biomacromolecules. 2011;12(5): 1724-1730.

30. Huang SJ, Sun SL, Feng TH, et al. Folate-mediated chondroitin sulfatepluronic 127 nanogels as a drug carrier. Eur J Pharm Sci. 2009;38(1): 64-73.

31. Xi JQ, Zhou L, Fei YH. Preparation of chondroitin sulfate nanocapsules for use as carries by the interfacial polymerization method. Int J Biol Macromol. 2012;50(1):157-163.

32. Xi JQ, Zhou L, Dai Hua. Drug-loaded chondroitin sulfate-based nanogels: Preparation and characterization. Colloid Surface B. 2012;100(12):107-115.

33. Zhu A, Pan Y, Dai S, et al. Preparation of N-maleoylchitosan nanocapsules for loading and sustained release of felodipine. Biomacromolecules. 2009;10(7):1997-2002.

34. Wang SC, Chen BH, Wang LF, Chen JS. Characterization of chondroitin sulfate and its interpenetrating polymer network hydrogels for sustaineddrug release. Int J Pharm. 2007;329(1-2):103-109.

35. Gao Q, Xu Y, Wu D, Sun Y, Li X. pH-responsive drug release from polymer-coated mesoporous silica spheres. J Phys Chem C. 2009;113(29):12753-12758.

36. Shi X, Wang Y, Varshney RR, Ren L, Zhang F, Wang DA. In-vitro osteogenesis of synovium stem cells induced by controlled release of bisphosphate additives from microspherical mesoporous silica composite. Biomaterials. 2009;30(23-24):3996-4005. 


\section{Supplementary figures}
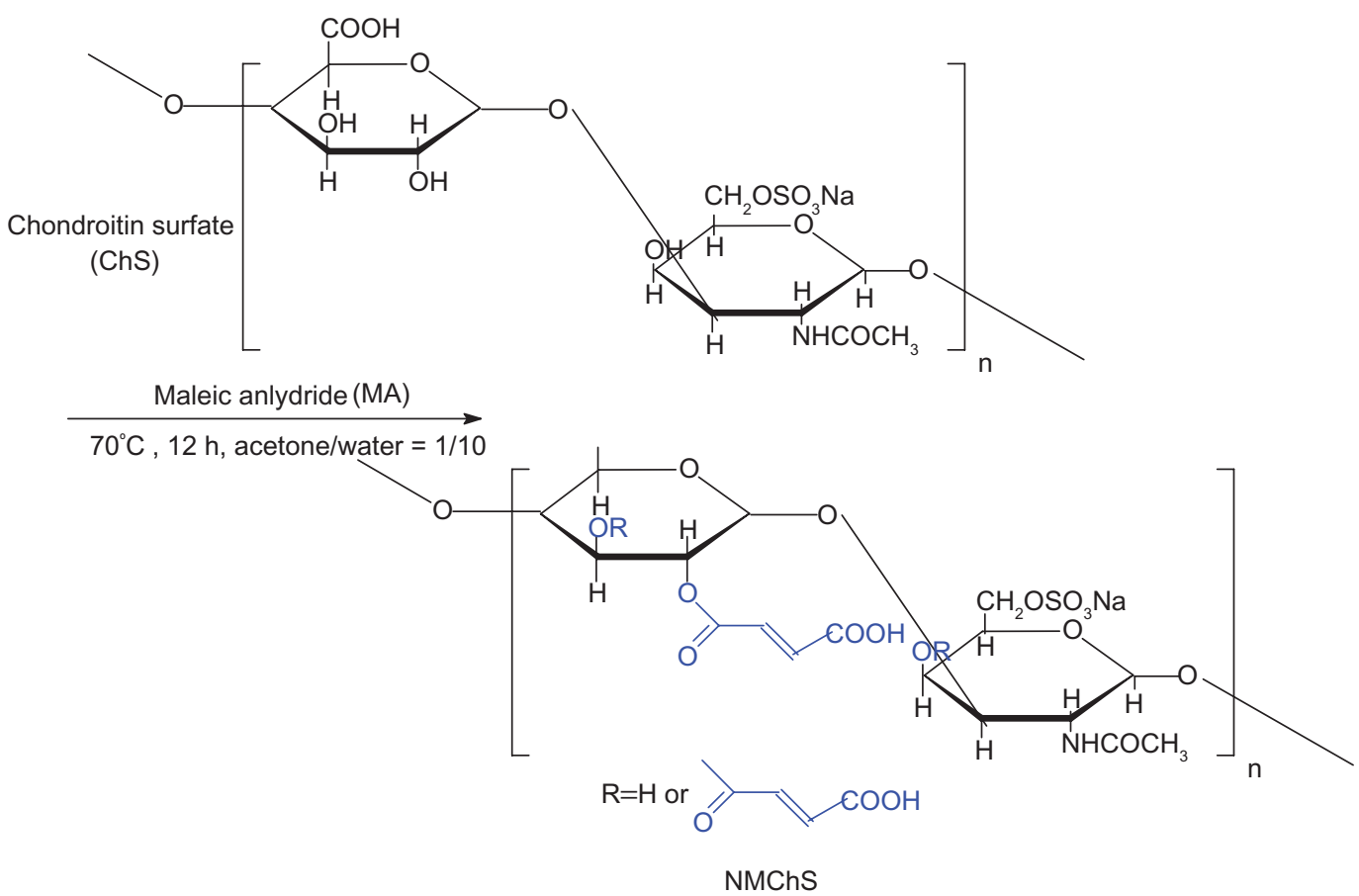

Scheme SI Synthesis pathway of macromer NMChS.

Abbreviation: NMChS, O-maleyl chondroitin sulfate.

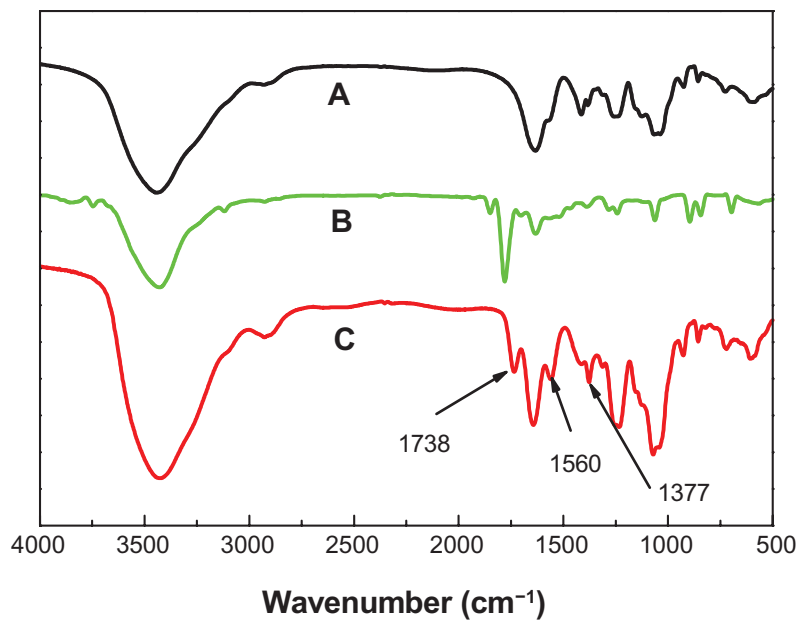

Figure SI FT-IR spectra of ChS, maleic anhydride and macromer NMChS. (A) rare ChS; (B) maleic anhydride and (C) macromer NMChS.

Abbreviations: FT-IR, fourier transform infrared; NMChS, O-maleyl chondrotin sulfate; ChS, chondrotin sulfate. 

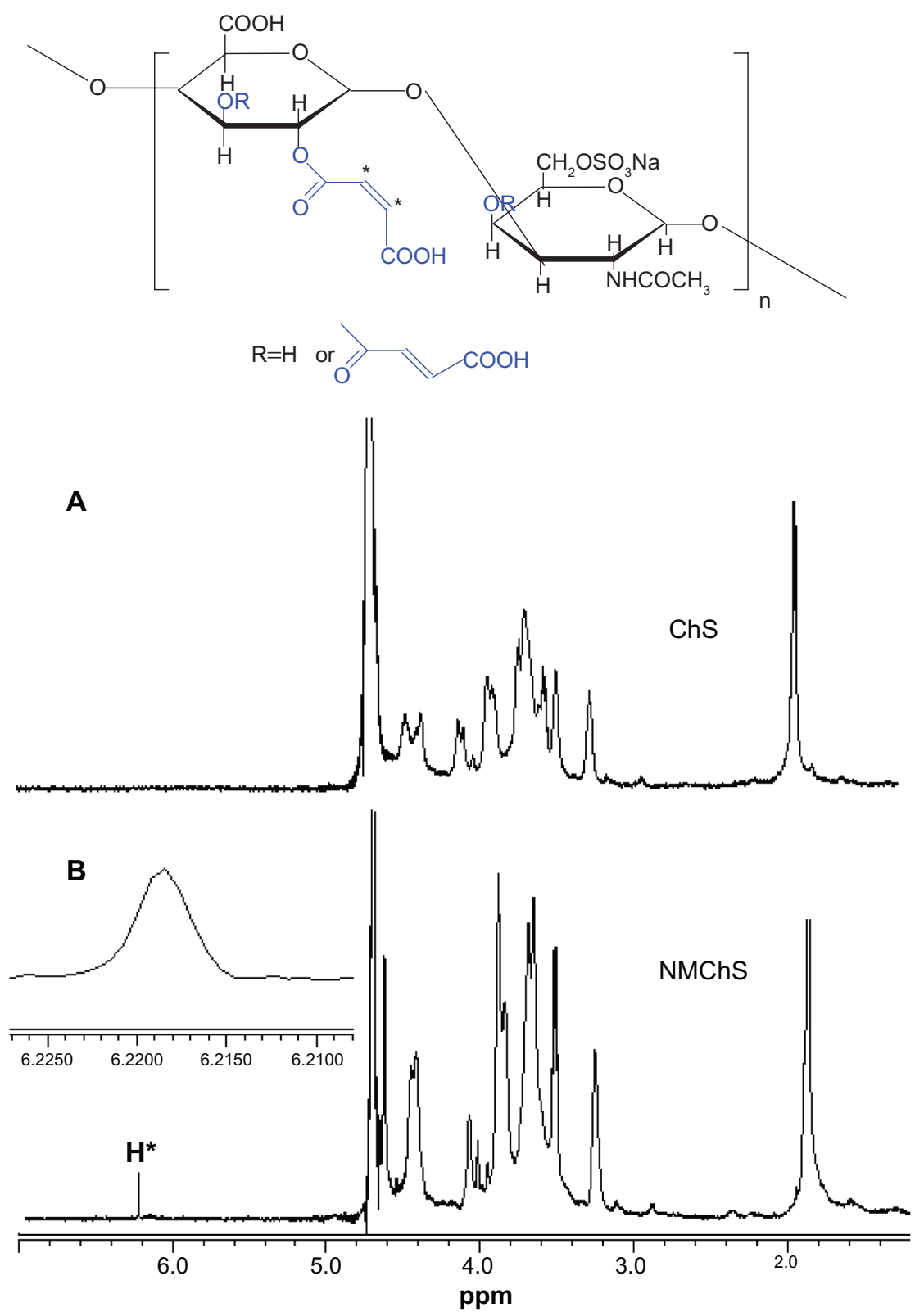

Figure S2 'H NMR spectra of the rare ChS (A) and synthesized NMChS (B).

Abbreviations: 'HNMR, nuclear magnetic resonance spectroscopy; NMChS, O-maleyl chondrotin sulfate; ChS, chondrotin sulfate.
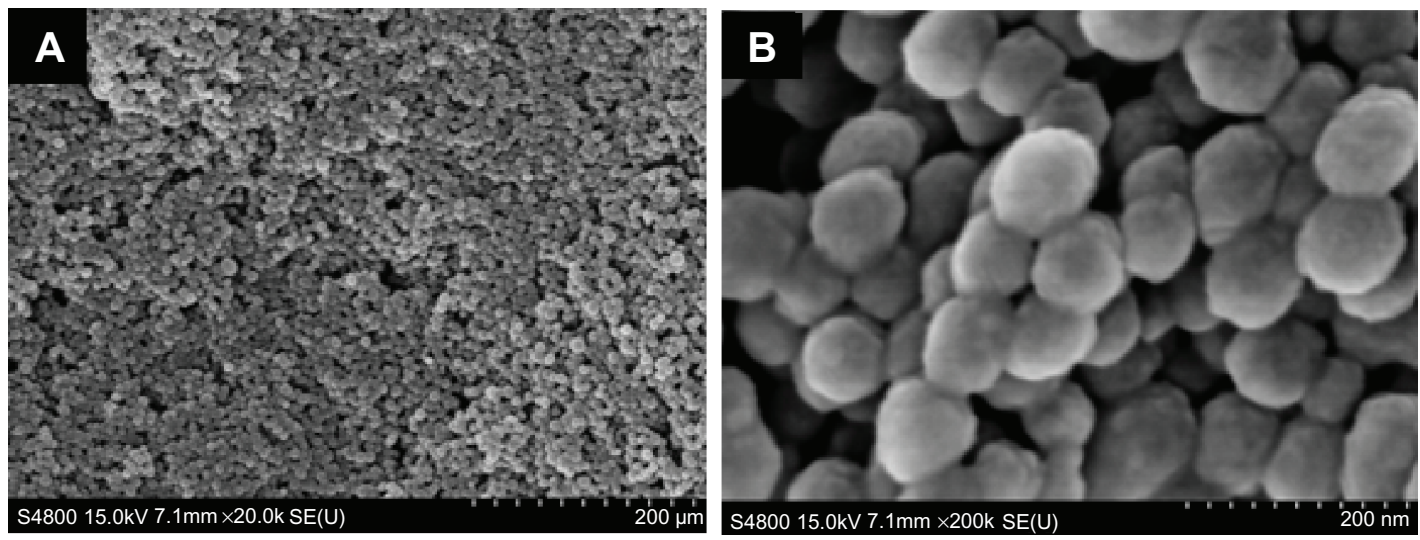

Figure S3 FESEM image of MSNs. (B) is higher magnification than (A).

Abbreviations: FESEM, field emission scanning electron microscopy; MSN, mesoporous silica nanoparticles. 
International Journal of Nanomedicine

Dovepress

\section{Publish your work in this journal}

The International Journal of Nanomedicine is an international, peerreviewed journal focusing on the application of nanotechnology in diagnostics, therapeutics, and drug delivery systems throughou the biomedical field. This journal is indexed on PubMed Central, MedLine, CAS, SciSearch ${ }^{\circledR}$, Current Contents ${ }^{\circledR} /$ Clinical Medicine,
Journal Citation Reports/Science Edition, EMBase, Scopus and the Elsevier Bibliographic databases. The manuscript management system is completely online and includes a very quick and fair peer-review system, which is all easy to use. Visit http://www.dovepress.com/ testimonials.php to read real quotes from published authors.

Submit your manuscript here: http://www.dovepress.com/international-journal-of-nanomedicine-journal 